\title{
Avaliação da atividade mutagênica da infusão de Baccharis trimera (Less.) DC. em teste de Allium cepa e teste de aberrações cromossômicas em linfócitos humanos
}

\author{
Daiane S. de Pinho, ${ }^{1}$ Régis T. Sturbelle, ${ }^{1}$ Maria da Graça Martino-Roth, ${ }^{* 1}$ Gilberto L. Garcias ${ }^{1,2}$
}

\author{
${ }^{1}$ Universidade Católica de Pelotas, Rua Félix da Cunha, 412, Centro, 96010- 000 Pelotas-RS, Brasil \\ ${ }^{2}$ Universidade Federal de Pelotas, Campus Universitário, s/nº, Caixa Postal 354, 96010-900, Pelotas-RS, Brasil.
}

\begin{abstract}
RESUMO: A carqueja (Baccharis trimera (Less.) DC.) é uma planta medicinal da família Asteraceae muito utilizada como chá no sul do Brasil no tratamento de doenças renais, intestinas, estomacais e principalmente como emagrecedora. O objetivo desde trabalho foi de avaliar a mutagenicidade in vivo e in vitro do chá e para isso foi realizado o teste de Allium cepa L. e o de aberrações cromossômicas em linfócitos humanos utilizando quatro tratamentos: T1 (água); T2 (20 g/L de carqueja); T3 (200 g/L de carqueja), e T4 (paracetamol, a $400 \mathrm{mg} / \mathrm{L}$ ). Ambos os procedimentos foram analisados pelo teste Mann-Whitney U. Este estudo evidencia um efeito mutagênico do chá em células vegetais (Allium cepa) e em células humanas (aberrações cromossômicas) cultivadas, pois em ambos os testes, T2 e T3 obteve-se uma média mais elevada que nos outros tratamentos. Este estudo demonstra que o efeito é dependente da dose, portanto recomenda-se que o chá de carqueja seja consumido com moderação.
\end{abstract}

Unitermos: Mutagenicidade, Baccharis trimera, Asteraceae, teste Allium cepa, teste aberrações cromossômicas.

\begin{abstract}
Evaluation of mutagenic activity resulting from the infusion Baccharis trimera (Less.) DC. using the Allium cepa test and a chromosomal test for aberrations in human lymphocytes". Broom (Baccharis trimera (Less.) DC.) is a medicinal plant from Asteraceae that is commonly used as a tea in the south of Brazil for the treatment of renal, intestinal and stomach diseases. It is also used as a slimming agent. The aim of this study was to evaluate the mutagenicity of the tea in vivo and in vitro. In order to do this, the Allium cepa test was carried out and the chromosomal aberrations in human lymphocytes were tested using four treatments: T1 (water); T2 (20 g/L of broom); T3 (200 g/L of broom) and T4 (paracetamol at $400 \mathrm{mg} / \mathrm{L}$ ). Both procedures were analyzed using the Mann-Whitney $U$ test. This study provided evidence of a mutagenic effect of the tea in vegetable cells (Allium cepa) and in cultivated human cells. In tests T2 and T3 there was a higher average than the other treatments. This study shows that the effect is dependent on the dose. It is therefore recommended that broom tea be consumed with moderation.
\end{abstract}

Keywords: Mutagenicity, Baccharis trimera, Asteraceae, Allium cepa test, chromosomal aberration test.

\section{INTRODUÇÃO}

No Brasil, as plantas medicinais da flora nativa são consumidas com pouca ou nenhuma comprovação de suas propriedades farmacológicas, propagadas por usuários ou comerciantes. Muitas vezes essas plantas são, inclusive, empregadas para fins medicinais diferentes daqueles utilizados pelos silvícolas. A toxicidade de plantas medicinais é um problema sério de saúde pública. Os efeitos adversos dos fitomedicamentos, possíveis adulterações e toxidez, bem com a ação sinergística (interação com outras drogas) ocorrem comumente. As pesquisas realizadas para a avaliação do uso seguro de plantas medicinais e fitoterápicos no Brasil ainda são incipientes, assim como o controle da comercialização pelos órgãos oficiais em feiras livres, mercados públicos ou lojas de produtos naturais (Veiga et al., 2005).

Podemos dizer que cada vegetal que apresenta propriedades medicinais é, por analogia, um frasco que contém diversos medicamentos juntos. Como seres vivos, os vegetais produzem substâncias químicas, como também os animais o fazem, e estas substâncias, muitas delas somente sintetizadas pelas plantas, são capazes de causar reações no organismo humano e ajudar a manter a homeostasia, isto é, o equilíbrio necessário para a manutenção de um organismo saudável. É válido ressaltar que substâncias que 
em princípio podem ser consideradas como terapêuticas também podem causar efeitos indesejados ou tóxicos. Os princípios ativos são os componentes químicos existentes na planta que conferem sua ação terapêutica peculiar. É incorreto pensar que as plantas são benéficas ao organismo humano somente por serem plantas, ou seja, elas devem conter substâncias farmacologicamente ativas (princípios ativos) para que atuem de alguma forma no corpo. Por isso, não há sentido em dizer que os medicamentos sintetizados por vegetais ou aqueles sintetizados pela mão do homem (portanto artificialmente) são diferentes entre si ou que aqueles provindos de plantas são melhores. Na verdade, as substâncias são idênticas, podendo ser menos tóxicas devido às baixas concentrações encontradas nos vegetais ou pela interação direta ou indireta com outras substâncias existentes na planta. Apesar disso, a fitoterapia atualmente está bastante difundida, principalmente por utilizar fármacos com menor toxicidade (em geral) e menor custo (Corrêa et al, 2005).

Apesar do uso terapêutico das plantas medicinais e de seus produtos (chás e tinturas), em certos casos, elas podem tornar-se um problema, pois algumas das substâncias que as compõem podem desencadear efeitos deletérios que resultam em um quadro clínico severo, algumas vezes, fatal. Em 1999, foram registrados 66584 casos de intoxicação humana no Brasil, onde somente a Região Sul foi responsável por 29,1\% destes casos. Entre os grandes centros desta, Porto Alegre destaca-se como a cidade com maior número de registros de intoxicação humana por plantas, sendo a sua quase totalidade na zona urbana (Sinitox, 1999).

Mais de 150000 espécies de plantas tem sido estudadas e muitas delas contém substâncias terapêuticas, que podem ser extraídas e usadas no preparo de drogas ou usadas diretamente como medicação, que é uma prática popular em determinados povos. Entretanto, as plantas medicinais, em geral sintetizam substâncias tóxicas, que in natura agem como uma defesa contra infecções, insetos e herbívoros, e podem afetar o organismo que faz uso delas. Portanto, se faz necessárias avaliações do potencial de citotoxicidade e mutagenicidade dessas plantas para o seu uso (Teixeira et al., 2003).

A carqueja, também chamada de carqueja-amarga, ocorre espontaneamente em quase todo país, crescendo abundantemente em regiões de campos, pastagens, beira de estradas, linhas de cercas, terrenos baldios, terrenos secos e pedregosos, e também nos lugares úmidos, ribanceira de rios, etc (Simões et al, 1998).

Esta espécie é utilizada principalmente como, colagoga e protetora hepática (Giuliano, 2000). Tradicionalmente é administra como infusão e se emprega como analgésica, diurética e para doenças renais, estomacais, e intestinais (Di Stasi et al., 2002), para o tratamento de reumatismo (Nakasugi \& Komai, 1998), e também em casos de hipertensão e diabetes (Di Stasi et al., 2002). Os diabéticos têm usufruído desta planta, devido aos seus princípios ativos amargos, influenciando bastante o pâncreas, a produzir mais insulina e ajudando a normalizar a glicemia nos portadores de diabetes tipo II (Franco, 2001). Usase também para promover a fertilidade feminina e para o tratamento de impotência masculina (Poser \& Mentz, 1999). Outros usos tradicionais são: antihelmíntica, antiviral, antifebril, analgésica e no tratamento da lepra. No Uruguai a população rural a utiliza como regulador da fertilidade e abortiva (Mangiaterra, 2005).

Devido a grande popularidade do chá de carqueja e de seu amplo uso, objetivou-se neste trabalho avaliar a mutagenicidade do chá de carqueja em dois testes, um in vivo e o outro in vitro, em ponta de raíz de Allium cepa e o outro através do teste de aberrações cromossômicas em linfócitos de sangue humano.

\section{MATERIAL E MÉTODOS}

\section{Material vegetal}

A carqueja, Baccharis trimera, foi obtida com a Dr ${ }^{a}$ Luciana Bicca Dode, no horto de sua propriedade, no endereço Rua Adolfo Fetter, 6040 e a identificação foi realizada pela Dr ${ }^{\mathrm{a}}$ Maria Antonieta Decio da Costa, Doutora em Ciências e professora de botânica da Universidade Católica de Pelotas.

A secagem da planta foi realizada de forma natural. As folhas secas foram colocadas em um recipiente e imersas em água fervente, ficando cobertas por $15 \mathrm{~min}$. A infusão foi extraída e resfriada. As soluções testes constaram de quatro tratamentos (com quatro repetições cada): T1 (controle negativo), onde as raízes dos bulbos ficaram imersas em água; T2, tratamento com infusão a $20 \mathrm{~g} / \mathrm{L}$ (dose usual) de carqueja; T3 (dez vezes mais concentrada), com infusão a $200 \mathrm{~g} / \mathrm{L}$ e T4 (controle positivo) com paracetamol (acetamidofenol), a $400 \mathrm{mg} / \mathrm{L}$.

\section{Teste em raíz de Alliun cepa $\mathbf{L}$.}

Os bulbos de Allium cepa L. foram colocados em frascos com água aerada para enraizar e quando as raízes alcançaram $5 \mathrm{~cm}$, foram colocadas submersas nas respectivas infusões por 48 h. As lâminas foram avaliadas em teste cego, usando microscópio ótico com 1000 vezes de aumento. Foram analizadas 2000 células por repetição, totalizando 8000 células para cada tratamento. Foi avaliado o índice mitótico (IM), as anomalias do ciclo mitótico (ACM), as anomalias interfásicas (AI), como células micronucleadas (CMN), binucleadas (CBN), com núcleos ligados (CNL) e o total de anomalias (TA).

\section{Teste de aberrações cromossômicas em linfócitos de sangue periférico humano}

A técnica utilizada foi o cultivo de linfócitos de sangue periférico (Moorhead et al.,1960), o qual foi obtido 
de quatro (repetições) indivíduos (dois homens e duas mulheres), saudáveis, aparentemente sem infecções, que não estivessem em tratamento nos últimos seis meses, com aproximadamente 20 anos de idade. Após 48 h de cultivo, foi adicionado ao meio $0,1 \mathrm{~mL}$ de infusão de Baccharis trimera, preparada em duas concentrações: T2 (dose usual de carqueja) $20 \mathrm{~g} / \mathrm{L}$ e T3 (dose dez vezes mais concentrada) com 200 g/L. O controle positivo (T4) foi tratado com $400 \mathrm{mg} / \mathrm{L}$ de paracetamol e o controle negativo com água aerada. As microculturas de sangue periférico humano foram preparadas de acordo com Moorhed et al. (1960) e utilizadas para determinar a freqüência e a distribuição de aberrações cromossômicas. Cem (100) metáfases foram analizadas, em teste cego, de cada repetição. Foram analisados o índice mitótico (IM), as anomalias estruturais (AE), as anomalias numéricas (AN) e o total de anomalias (TA). Em ambos os testes os dados foram armazenados em banco de dados no programa SPSS, versão 10.0 "for Windows” e analisados pelo teste de, Mann-Witney-U, com um nível de significância de $\mathrm{p}<0,05$.

\section{RESULTADOS}

\section{Teste de Allium cepa}

O IM apresentou-se elevado em T1 e T2 e diminuiu nos demais tratamentos. Relacionado ao IM, a média do número de células em divisão diferiu significativamente entre o controle (T1) e os tratamentos com a dose mais concentrada e o paracetamol, evidenciando que houve inibição da divisão celular nesses dois tratamentos (T3 e T4) e que T3 foi a dosagem com um efeito mais drástico sobre as células meristemáticas das raízes de Allium cepa.

Quanto as ACM (as mais freqüentemente observadas foram pontes e fragmentos anafásicos (Figura 1), os resultados foram diferentes do que se esperava, pois T3 e T4 apresentaram menor média do que T1. Porém, pode-se concluir que o controle apresentou uma média maior de ACM do que T3 e T4, devido a grande redução do número de células em divisão nesses dois tratamentos. Isso pode ser confirmado pelos resultados observados de AI.

OnúmeromédiodeAIfoisignificativamentemenor em T1 do que nos demais tratamentos que não diferiram entre si. Todas as dosagens de infusão de carqueja, bem como a solução de paracetamol determinaram alterações interfásicas de mesma intensidade, sendo observada uma mesma proporção de células com micronúcleos, binucleadas e com núcleos ligados. Ao analisar o total de anomalias (TA), foram detectados resultados semelhantes as AI, com o tratamento controle diferindo significativamente dos demais e estes não diferindo entre si.

Estes resultados demonstraram que a divisão celular foi acentuadamente diminuida pelo tratamento com a dose mais elevada e que juntamente com a dose usual e o paracetamol determinaram um aumento significativo de anomalias interfásicas. Pode se verificar algumas anomalias na Figura 1, e a Tabela 1 ajuda a esclarecer os resultados.

\section{Teste de aberrações cromossômicas em linfócitos de sangue humano}

Através do teste de aberrações cromossômicas em linfócitos humanos, procurou-se também, avaliar o potencial mutagênico de carqueja (Baccharis trimera) que é popularmente utilizada pela população em geral, com inúmeras finalidades. Foram analizados o índice mitótico (IM), as anomalias estruturais (AE), as anomalias numéricas (AN) e o total de anomalias (TA) (Tabela 2). As médias das células em divisão (CD) e o índice mitótico (IM) apresentaram-se elevadas em T1 e diminuiram nos demais tratamentos, porém não diferindo significativamente dos demais tratamentos, evidenciando que a infusão de carqueja nas duas dosagens, bem como o paracetamol não inibiram a divisão celular em teste de linfócitos. Quanto as $\mathrm{AE}, \mathrm{T} 3$ diferiu de todos os tratamentos, pois apresentou um elevado número de separações das cromátides irmãs nas células metafásicas de linfócitos. T1e T2 não diferiram de T4, sendo que T1 apresentou a menor média. Pode-se concluir que a dose dez vezes mais elevada de carqueja foi danosa para as células. O número médio de AN foi relativamente maior em $\mathrm{T} 3$ do que nos demais tratamentos. Sendo que T1 diferiu de T2 e T3, mas não diferiu de T4. T2 e T3 não diferiram entre si. Com relação às células hiperdiplóides, não houve diferença entre os tratamentos, porém T3 teve maior média e T1 menor média, já nas células hipodiplóides, T1 não diferiu de T4, já os demais

Tabela 1. Índice mitótico, número médio e desvio padrão de células em divisão, com anomalias do ciclo mitótico, com anomalias interfásicas e com o total de anomalias observadas em teste de Allium cepa L.

\begin{tabular}{lccccc}
\hline Tratamentos & CD & IM & ACM & AI & TA \\
& X/DP & $\%$ & X/DP & X/DP & X/DP \\
\hline T1 & $146,84 \pm 64,61^{\mathrm{a}, \mathrm{b}, \mathrm{c}}$ & 23,86 & $6,76 \pm 5,58^{\mathrm{g}, \mathrm{h}}$ & $1,00 \pm 1,08$ & $7,53 \pm 5,95^{\mathrm{m}, \mathrm{n}, \mathrm{o}}$ \\
T2 & $109,25 \pm 87,46^{\mathrm{a}, \mathrm{d}, \mathrm{e}}$ & 21,85 & $19,43 \pm 35,44^{\mathrm{i}}$ & $40,81 \pm 29,90^{\mathrm{j}, 1}$ & $60,25 \pm 58,34^{\mathrm{m}}$ \\
T3 & $4,25 \pm 4,86^{\mathrm{b}, \mathrm{d}, \mathrm{f}}$ & 0,85 & $0,81 \pm 1,27^{\mathrm{g}, \mathrm{i}}$ & $33,50 \pm 20,25^{\mathrm{j}}$ & $34,18 \pm 20,42^{\mathrm{n}}$ \\
T4 & $32,37 \pm 33,43^{\mathrm{c}, \mathrm{e}, \mathrm{f}}$ & $6,47^{\mathrm{f}}$ & $1,26 \pm 1,57^{\mathrm{h}}$ & $40,37 \pm 37,90^{{ }^{1}}$ & $41,31 \pm 37,93^{\circ}$ \\
\hline
\end{tabular}

CD- células em divisão; IM- índice mitótico; ACM- anomalias do ciclo mitótico; AI- anomalias interfásicas; TA- total de anomalias; a, b, c, d, e, f, g, h, i, j, l, m, n, o = p < 0,05. 
Tabela 2. Índice mitótico, média e desvio padrão do número de células em divisão, anomalias estruturais, anomalias numéricas e total de anomalias observadas no teste de aberrações cromossômicas.

\begin{tabular}{lccccc}
\hline Tratamentos & CD & IM & AE & AN & TA \\
& X/DP & $\%$ & X/DP & X/DP & X/DP \\
\hline T1 & $7,75 \pm 3,20$ & 7,8 & $8,25 \pm 1,70^{\mathrm{a}}$ & $5,75 \pm 0,95 \mathrm{~d}$ & $14,00 \pm 2,444^{\mathrm{g}, \mathrm{h}}$ \\
T2 & $4,00 \pm 0,82$ & 4,03 & $19,50 \pm 5,25^{\mathrm{a}, \mathrm{b}}$ & $10,00 \pm 1,41^{\mathrm{d}, \mathrm{e}}$ & $29,50 \pm 6,45^{\mathrm{g}, \mathrm{i}}$ \\
T3 & $5,00 \pm 1,41$ & 5,02 & $78,25 \pm 24,74^{\mathrm{a}, \mathrm{b}, \mathrm{c}}$ & $14,75 \pm 2,21^{\mathrm{d}, \mathrm{e}, \mathrm{f}}$ & $93,00 \pm 23,95^{\mathrm{h}, \mathrm{i}, \mathrm{j}}$ \\
T4 & $6,00 \pm 0,82$ & 6,07 & $15,50 \pm 6,60^{\mathrm{c}}$ & $8,50 \pm 3,69^{\mathrm{f}}$ & $24,00 \pm 10,09^{\mathrm{j}}$ \\
\hline
\end{tabular}

CD- células em divisão; IM- índice mitótico; AN- anomalias cromossômicas numéricas; AE-anomalias cromossômicas estruturais; TA- total de anomalias. a, b, c, d, e, f, g, h, i, , j =p $<0,05$.
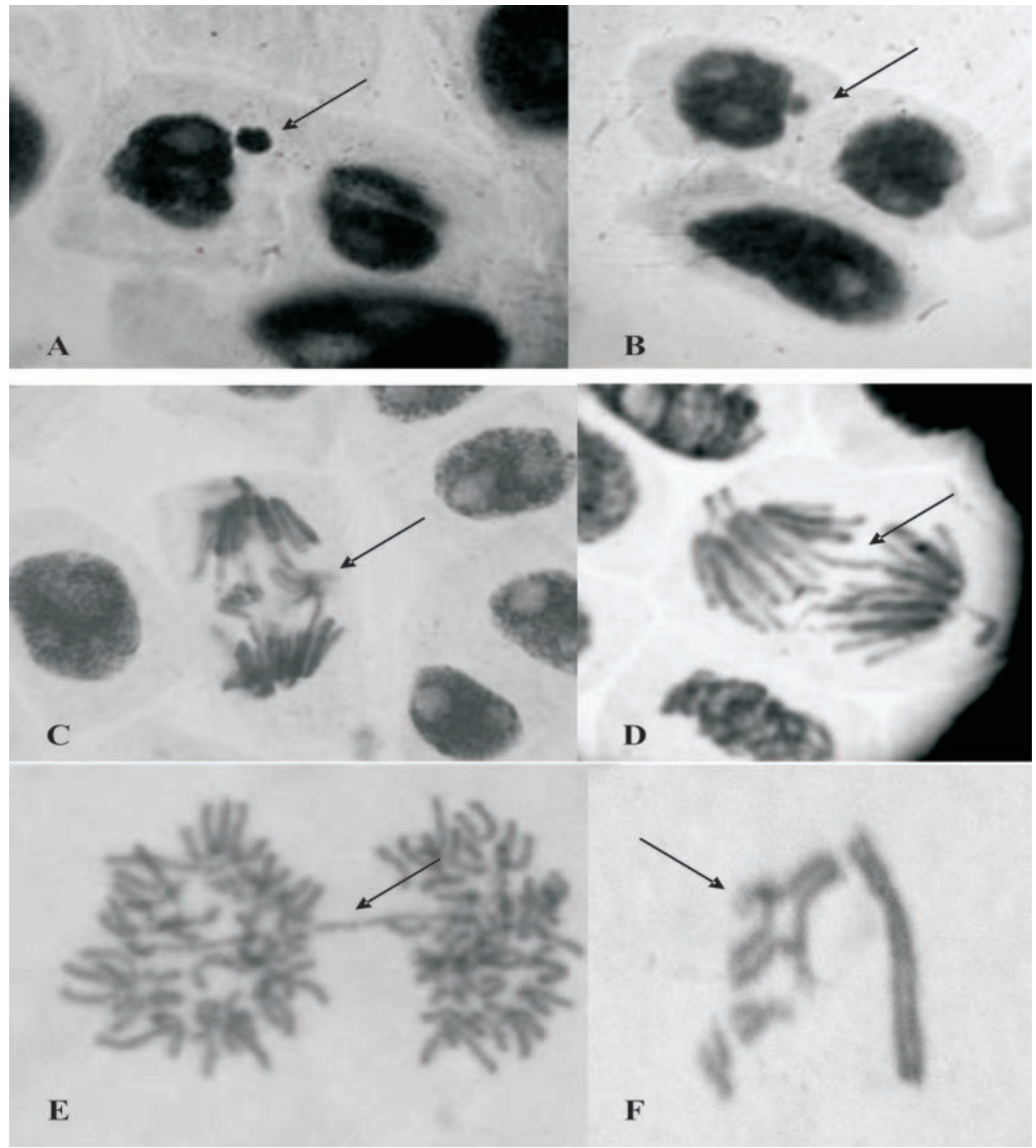

Figura 1. Anomalias observadas em células de Allium cepa, após o tratamento com infusão de carqueja. A. Micronúcleo; B. Broto; C. Anáfase multipolar; D. Ponte anafásica. Anomalias observadas em células de sangue periférico humano, após o tratamento com infusão de carqueja: E. Ponte; F. Cromossomos triradiais. Fonte: Laboratório de Genética, Escola de Saúde, Universidade Católica de Pelotas.

tratamentos diferiram entre si, sendo que T3 apresentou maior média e T1 menor média. Ao analisar o total de anomalias (TA), foram detectados resultados semelhantes às $\mathrm{AE}$ e $\mathrm{AN}$, com o $\mathrm{T} 3$ diferindo significativamente dos demais tratamentos e T1 e T2 não diferindo de T4.
Estes resultados demonstraram que a dose usual de carqueja (T2) não inibiu a divisão celular e, que T3 (dose dez vezes mais concentrada) aumentou o número de anomalias estruturais, numéricas e gerais. 


\section{DISCUSSÃO}

Este trabalho procurou avaliar o efeito da infusão de carqueja (Baccharis trimera) sobre células de ponta de raíz de Allium cepa e sobre cromossomos de linfócitos humanos cultivados. A carqueja é uma planta utilizada em grande escala com a finalidade de aliviar sintomas de vários males e, pouco se sabe sobre seu efeito. A carqueja, assim como as outras plantas medicinais possui em sua constituição substâncias que podem ser benéficas ou não aos outros organismos. Pouco se sabe se a carqueja possui efeito genotóxico, ou seja, se pode ser tóxica para o material genético que foi o objetivo deste estudo.

No teste de Allium cepa foi avaliado o índice mitótico e verificou-se que a concentração mais alta, da infusão de carqueja diminuiu o índice mitótico. Avancini et al. (2000) verificaram a atividade antimicrobiana in vitro do decocto de $B$. trimera por meio de testes-padrão internacionais e concluíram ter a carqueja ação como desinfetante e anti-séptica. O que pode estar relacionado com o fato das infusões de carqueja inibirem a divisão celular de células de Allium cepa.

Em outro estudo, verificou-se que o extrato bruto aquoso de $B$. trimera na concentração de $20 \%$ $(\mathrm{p} / \mathrm{v})$, inibiu a germinação de sementes de picão (Bidens pilosa), diferindo do tratamento teste com água destilada (Cruz et al., 2000). Já Stangarlin et al. (1999) em seus estudos, demonstraram que o extrato bruto de B. trimera inibiu parcialmente o crescimento micelial dos fungos fitopatógenos Rbizoctonia solani, Sclerotium rolfsii, Alternaria alternata e Phytophthora sp.

Para verificar sua ação genotóxica, foram analisadas as anomalias do ciclo mitótico (ACM) e interfásicas (AI), sendo observado que houve aumento de ACM apenas com a concentração mais alta e houve aumento da AI, assim como, do total de anomalias, sugerindo uma ação mutagênica da carqueja sobre as células de Allium cepa. Já em células de hepatoma de rato, o estudo de Passares et al., (2004), no qual realizaram o ensaio cometa, apenas detectaram um discreto efeito genotóxico dose dependente. Em Salmonella (teste de Ames), Borgo et al. (2004) avaliaram mutagenicidade por erro de leitura, substituição de bases e por danos oxidativos de infusão de $B$. articulata e verificaram atividade mutagênica direta, sendo predominante a mutação por erro de leitura do código genético. Como pode se observar nos estudos citados houve ação mutagênica da carqueja e, dependendo do organismo que foi usado para teste, estes resultados são mais ou menos evidentes. Para verificar o efeito das infusões de carqueja em células humanas, se utilizou o teste de aberrações cromossômicas em linfócitos cultivados. Observou-se que enquanto nas células de Allium cepa houve um decréscimo do IM, nas células humanas isso não aconteceu. Apresentando, portanto um efeito diferenciado em células vegetais e humanas. Foram avaliadas também as anomalias numéricas e estruturais dos cromossomos humanos e verificou-se um aumento dose dependente de ambas as alterações. Esse fato sugere que as duas concentrações da infusão de carqueja causam mutações em células humanas in vitro.

Não se encontrou na literatura estudos similares e isto é compreensível, tendo em vista que a preocupação com o possível efeito danoso das plantas medicinais é relativamente novo. Alguns estudos avaliam a toxicidade de B. trimera em animais, como o trabalho de Fonseca et al. (2003), no qual os pesquisadores analisaram os teores de aspartato transaminase (ALT) em ratos submetidos a tratamentos com infusões de carqueja (T1-controle, T2- 1 g/150 mL, T3-3 g/150 mL, e T4-6 g/150 mL). Após 28 dias de tratamento a analise do sangue desses animais demonstraram um aumento crescente dose dependente dos teores de ALT, indicando toxicidade hepática causada pela carqueja.

Esses resultados se opõem ao estudo de Gamberini et al. (1992), onde foi demonstrado a não toxicidade em ensaios com roedores e também Pedrazzi et al. (1997) realizaram teste oral de toxicidade (aguda e crônica) em ratos, administrando infusões a $2 \mathrm{~g}$ da planta em $40 \mathrm{~mL}$ de água. O resultado deste teste não demonstrou sinais de toxicidade.

Conclui-se, portanto que em células de raíz de Allium серa, a dose usual do chá de carqueja (20 gL) aumentou o número de anomalias do ciclo mitótico, já a dose dez vezes mais concentrada (200 gL), inibiu a divisão celular e ambas as concentrações aumentaram o número de anomalias interfásicas. Em linfócitos humanos, não houve atuação de inibição na divisão celular, porém houve aumento dose-dependente de anomalias cromossômicas e numéricas e estruturais. Este estudo evidencia, portanto um efeito mutagênico do chá em células vegetais (Allium сера) e em células humanas (aberrações cromossômicas) cultivadas. E demonstra que o efeito é dependente da dose, portanto recomenda-se que o chá de carqueja seja consumido com moderação.

\section{AGRADECIMENTOS}

À Universidade Católica de Pelotas e ao Curso de Ciências Biológicas, especialmente ao Laboratório de Genética, pela oportunidade do desenvolvimento deste trabalho e aos colegas Patrícia Mayer e Gilles Tedesco pelo apoio e auxílio na realização deste projeto.

\section{REFERÊNCIAS BIBLIOGRÁFICAS}

Avancini CAM, Wiest IM Mundstock E 2000. Atividade bacteriostática e bactericida do decocto de Baccharis trimera (Less) DC., Compositae, carqueja, como desinfetante ou anti-séptico. Arq Bras Med Vet Zootec, p. 264-270.

Borgo J, Rosa DP, Vargas VMF 2004. Mutagenicidade do extrato aquoso de Baccharis articulata (Lam.) Person no ensaio 
salmonella/microssoma. Rev Bras Toxicol 17: 37-43.

Corrêa AD, Batista RS, Quintas LE. 2005. Plantas Medicinais: Do cultivo à terapêutica - Contém formulação e modo de preparo de cosméticos. 6 ed. Petrópolis: Vozes, p.103.

Cruz MES, Nozaki MH, Batista MA 2000. Plantas medicinais e alelopatia. Rev Biotecnol Cien Des 15: 42-45.

Di Stasi LC, Oliveira GC, Carvalhes MA 2002. Medicinal plants popularly used in Brazilian. Trop Atlantic Forest Fitoterapia 73: 69-91.

Fonseca LS, Dourado AS, Dourado MT 2003. Verificação do teor de AST (aspartato transaminase) e ALT (lamina transaminase) de ratas tratadas com infusões de carqueja. XI Encontro de Química da Região Sul: UFPEL. Pelotas, RS,

Franco L 2001. As sensacionais 50 plantas medicinais campeãs de poder curativo. 5 ed. Lobo Franco LTDA, p.46.

Gamberini M, Lapa A 1992. Ações antiúlcera e antiácida do extrato aquoso e das frações de B. trimera. Anais XII Simpósio de Plantas Medicinais do Brasil, UFP. Curitiba, Paraná.

Giuliano DA 2000. Subtribu Baccharinae: Baccharis. Fanerogâmica Argentina. Proflora Conicet 66: 6-67.

Mangiterra PA 2005. Evolução de parâmetros botânicos e fitoquímicos para o controle de qualidade da carqueja. Las tesinas de Belgrano, 190p. Faculdade de Ciências Exatas y Natureles de la Universidad de Belgrano.

Moorhead PS, Nowell PC, Mellman WJ, Battips DM, Hungerford DA 1960. Chromosome preparation of leucocytes cultured from human peripheral blood. Exp Cell Res 20: 613-615.

Nakasugi T, Komai K 1998. Antimutagens in the Brazilian flok medicinal planta carqueja (Baccharis trimera Less). J Agr Food Chem 46: 2560-2564.

Passares CPB, Nogueira NPA, Coelho MGP 2004. Estudo toxicológico da fração aquosa do extrato aquoso de Baccharis trimera. $13^{\circ}$ Semana de Iniciação Científica, UERJ, Farmacognosia. Instituto de Biologia Roberto Alcântara Gomes. Rio de Janeiro, RJ.

Pedrazzi AHP, Rodriguez ER, Zanardo-Filho A 1997. Hematological evaluation of carqueja (Baccharis trimera) infusion. Fitoterapia 68: 26-26.

Poser GL, Mentz LA 1999. Diversidade biológica e sistemas de classificação. In. Simões CMO, Schenkel EP, Gosmann G, Mello JCP, Mentz LA, Petrovick PR. Farmacognosia: da planta ao medicamento. Porto Alegre/Florianópolis: Ed. Universidade UFRGS/UFCS, p.75-89.

Simões C, Mentz L, Schenkel E, Irgang B, Stehmann J 1998 Plantas da medicina popular no Rio Grande do Sul. 5 ed., Porto Alegre: Ed. Universidade/UFRGS, p.67.

Sinitox (Sistema Nacional de Informações tóxicofarmacológicas). Estatística anual dos casos de intoxicações e envenenamentos: Brasil, 1999/Centro de Informação científica e Tecnológica. Rio de Janeiro: FIOCRUZ/CICT, 1999.

Stargalin JR, Schwan-Estrada KRF, Cruz MES, Nozaki MH 1999. Plantas medicinais e controle alternativo de fitopatógenos. Biotecnol Cien Des 11: 105-109.

Teixeira RO, Camparoto ML, Mantovani MS, Vicentini VEP 2003. Assessment of two medicinal plants, Psidium guajava L. and Achillea millefolium L., in vitro and in vivo assays. Genet Mol Bio 4: 551-555.

Veiga Jr,VF, Pinto AC, Maciel MAM 2005. Plantas Medicinais: cura segura? Quim Nova 28: 24-26. 